\title{
Paroxysmal Dyskinesia Associated with Hypoglycemia
}

\author{
Brian J. Schmidt and Neelan Pillay
}

\begin{abstract}
The association of movement disorders with hypoglycemia has been rarely noted in the past. We recently observed 2 patients with documented hypoglycemia and paroxysmal dyskinesias. One patient had evidence of an insulin-secreting tumor. The other patient had insulin-dependent diabetes, and also experienced recurrent episodes of hypoglycemic hemiparesis. Classical adrenergic symptoms of hypoglycemia were absent in both patients. Our observations support the concept that the development of neuroglycopenic symptoms cannot be predicted from blood glucose measurements alone, but must depend on other factors controlling the availability or metabolism of glucose in the brain.

RÉSUMÉ: Dyskinésies paroxystiques associées à l'hypoglycémie. L'association de désordres du mouvement avec l'hypoglycémie a rarement été notée dans le passé. Nous avons récemment observé 2 patients avec une hypoglycémie documentée et des dyskinésies paroxistiques. Un patient avait des manifestations cliniques associées à une tumeur secrétant de l'insuline. L'autre patient avait un diabète insulino-dépendant accompagné d'épisodes récurrents d'hémiparésie hypoglycémique. Les symptômes adrénergiques classiques d'hypoglycémie étaient absents chez ces deux patients. Nos observations appuient la notion que l'apparition de symptômes de neuroglycopénie ne peut être prédite sur la base de la glycémie seulement mais dépend d'autres facteurs contrôlant la disponibilité ou le métabolisme du glucose dans le cerveau.
\end{abstract}

Can. I. Neurol. Sci. 1993; 20: 151-153

In 1937 Golden described the occurrence of a variety of involuntary movements in psychiatric patients undergoing insulin-induced hypoglycemic shock treatment.' During deeper stages of coma, some patients developed "irregular, thrashing, apparently purposeless movements of the arms and legs" which Golden distinguished clinically from "true epileptic seizures" he had also observed in some patients. He further noted that similar involuntary movements had not been described in association with "accidental hypoglycemia arising as a complication of diabetic treatment nor as a symptom of pancreatic adenoma."

In more recent decades, since the abandonment of insulin shock therapy, the association of paroxysmal dyskinesias with hypoglycemia has been rarely documented. 2.3 .4 .5

We have recently seen 2 patients who presented with involuntary movements associated with episodic hypoglycemia. The first patient had a pancreatic tumor. The second patient had insulin-dependent diabetes mellitus and, in addition to paroxysmal dyskinesias, suffered episodes of alternating hemiparesis during hypoglycemia.

\section{Case Reports}

\section{Patient 1}

A 54-year-old man with chronic hypoglycemia of undetermined etiology presented with a 4-year history of episodic uncontrollable limb movements. The attacks usually began with a sudden "restless sensation" in his lower limbs, followed by chaotic thrashing of his legs and sometimes arms. He denied experiencing loss of consciousness, urinary incontinence or tongue biting during the attacks. When the episodes occurred at work, he usually would get out of his chair and lie on the floor to prevent injury. His coworkers would then give him orange juice which reliably aborted the attacks. The episodes lasted from 2 to 15 minutes and occurred approximately 10 to 15 times during the previous 12 months. The movements were not provoked by sensory stimulation nor by attempts to move his limbs.

In addition to the daytime attacks described above, his wife had frequently witnessed 2 types of early morning spells occurring around his usual time of awakening. One type of spell was similar to the daytime episodes of dyskinesia, except in his wife's opinion. he was also confused during the episode. A second type of early morning event did not include involuntary limb movements; instead it was characterized by passive confusion, staring and automatisms, and likely represented complex partial seizures. Either type of early morning attack was more likely to occur if he omitted his 2 a.m. snack, and resolved once his wife was able to get him to drink orange juice.

There was no history of adrenergic symptoms of hypoglycemia. such as diaphoresis, tremor or palpitations, during any of the episodes. Apart from hypoglycemia, he had no other medical illness. The only medication he was taking was diazoxide, which was prescribed to help control his hypoglycemia. There was no family history of movement disorders, seizures or any other form of neurological disease. Except for mild memory impairment for recent events, the rest of his mental status and neurological examination was normal.

The following laboratory investigations were normal: complete blood count; sedimentation rate; electrolytes; renal, liver, and thyroid

From the Section of Neurology, Department of Internal Medicine, Faculty of Medicine, University of Manitoba, Winnipeg

Received September 14, 1992. Accepted in final form January 13, 1993

Reprint requests to: Brian J Schmidt MD, Section of Neurology, Health Sciences Centre, 820 Sherbrook Street, Winnipeg Manitoba, Canada R3A IR9 
function tests; chest radiograph: CT scan of the brain; and 2 routine EEGs. His random blood glucose measurements ranged from $1.8-3.5$ $\mathrm{mmol} / \mathrm{l}$ (normal $3.6-6.1)$. The glycated hemoglobin $A_{1 \mathrm{c}}$ was also low at $3.64 \%$ (normal $4.3-7.0$ ). Fasting insulin levels were interpreted as inappropriately high for the degree of hypoglycemia. Abdominal $\mathrm{C} T$ and ultrasound studies failed to show an abnormality, however, an MRI scan demonstrated a $6 \mathrm{~mm}$ mass in the pancreas, presumed to be an insulin-secreting tumor.

\section{Video-EEG Recorded Event}

He was admitted to the neurology service for continuous video-EEG monitoring. An early morning attack was provoked by withholding his usual late evening and 2 a.m. snacks. At 0720 hours he awakened from light sleep. Several minutes later he developed twisting movements of the trunk as well as intermittent uncontrollable violent thrashing of the lower limbs. The upper limbs displayed milder dystonic and choreiform posturing. Abrupt head rotations to either side occurred several times as did brief episodes of facial grimacing. The movements waxed and waned in intensity as large amplitude ballistic movements intermixed with choreiform and dystonic components. Despite the chaotic movements, he appropriately responded to simple questions asked by nurses attending him during the episode. He was given orange juice, and the episode ended after 10 minutes in total duration. Throughout the episode, his EEG showed diffuse $5-6 \mathrm{~Hz}$ slowing compatible with a metabolic encephalopathy, which soon disappeared after receiving orange juice. His blood glucose was $2.1 \mathrm{mmol} / \mathrm{l}$ during the attack.

\section{Patient 2}

A 24-year-old woman with insulin-dependent diabetes mellitus presented with recurrent episodes of hemiparesis involving either side. Right hemiparetic spells were sometimes associated with aphasia. Several episodes were witnessed in hospital and typically occurred during early morning hours ( $2-6 \mathrm{a} . \mathrm{m}$.) with complete resolution over the course of 6 hours. There were no sensory symptoms and classical adrenergic symptoms of hypoglycemia were absent.

Besides episodes of hemiparesis she also reported separate attacks of choreiform movements, predominantly involving the upper limbs. The attacks were bilateral or unilateral involving either side, and lasted 1 to 2 hours. Similar to the hemiparetic episodes, the attacks of choreiform movements occurred in the early morning hours, and there was no impairment of consciousness nor any accompanying adrenergic symptoms.

She had a history of migraine, but did not experience headaches in association with the neurological symptoms described above. She also had a past history of complex partial seizures lasting 5 to 10 minutes that were well controlled by carbamazepine. Approximately $80 \%$ of the seizures were musicogenic and her blood glucose level was not depressed when measured during an EEG documented seizure. Clinical evidence of seizure activity was never witnessed in relation to the hemiparetic spells, nor in association with the attacks of arrhythmic involuntary movements. There was no family history of neurological symptoms. Her insulin dose was $18 / 8$ units (NPH/Regular) in the morning, $18 / 4$ units in the afternoon. Her neurological examination was normal between episodes.

The following laboratory investigations were normal: complete blood count; sedimentation rate; electrolytes; renal, liver, and thyroid function tests; CT scan of brain; and a routine EEG. The glycated hemoglobin $\mathrm{A}_{\mathrm{Ic}}$ was $9.5 \%$. Her blood glucose levels varied between 7 and $18 \mathrm{mmol} / \mathrm{l}$ and were generally lowest between 2 and 4 a.m.. During 2 of the early morning hemiplegic episodes her glucose levels were 2.3 and $4.1 \mathrm{mmol} / \mathrm{l}$ respectively.

\section{Video-EEG Recorded Event}

An attack of bilateral upper limb choreoathetotic movements was recorded during a trial of insulin-induced hypoglycemia. She also displayed mild confusion during the episode. Her blood glucose level was $6.0 \mathrm{mmol} / \mathrm{l}$ before the event and $2.0 \mathrm{mmol} / \mathrm{l}$ during the episode which was subsequently aborted by administration of intravenous glucose. No evidence of epileptiform activity was recorded on the EEG during the hypoglycemic period.

\section{Discussion}

Dyskinesias occur in a variety of hereditary, structural, infectious, metabolic, and toxic conditions. ${ }^{6}$ However, there are few disorders in which involuntary movements occur primarily as paroxysmal events and these can be broadly grouped into familial forms and those presumed to be secondary to an identifiable abnormality. The three main familial varieties are paroxysmal dystonic choreoathetosis, paroxysmal kinesigenic, and an intermediate type. ${ }^{7}$ Secondary forms of paroxysmal dyskinesia have been attributed to multiple sclerosis, head trauma, thalamic infarction, birth asphyxia, hypernatremia, thyrotoxicosis, and hypoparathyroidism. ${ }^{7}$

It is well known that besides diffuse cerebral manifestations such as coma, both hyperglycemia and hypoglycemia can induce either negative (e.g., hemiparesis, hemianopsia) or positive (e.g., seizures) focal neurological symptoms. ${ }^{8-10}$ Paroxysmal dyskinesia is another form of positive neurological symptom that has been reported in several patients with hyperglycemia. ${ }^{11-14}$

Our second patient illustrates that hypoglycemia may cause recurrent hemiplegia mimicking transient ischemic attacks. In their review of the literature, Foster and Hart noted that $86 \%$ of 29 patients with hypoglycemia-induced hemiplegia had diabetes mellitus and were receiving insulin or oral hypoglycemic drugs, and the attacks alternately involved the left or right side in $29 \% .^{15}$

We are aware of only 4 patients described in the recent literature with paroxysmal involuntary movements associated with hypoglycemia. Newman and Kinkel observed a 45-year-old woman with diabetes mellitus who had recurrent episodes of choreoathetosis and altered sensorium during insulin-induced hypoglycemic episodes. ${ }^{2}$ Haan et al. reported an 80 -year-old woman who initially presented with hyperglycemia, seizures and hemiparesis, but following treatment developed fluctuating choreoathetotic movements whenever the blood glucose level decreased below $5 \mathrm{mmol} / \mathrm{l} .{ }^{3}$ Prajua et al. documented the occurrence of paroxysmal choreoathetosis in a 55-year-old male with alcohol-induced hypoglycemia. ${ }^{4}$ Sudhakar et al. described a 49year-old male with a 10 -year history of episodic involuntary movements associated with hypoglycemia of undetermined etiology.

Our first patient was found to have a pancreatic tumor that was presumably the source of the inappropriately elevated insulin levels. To our knowledge however, the occurrence of paroxysmal dyskinesias has not previously been noted in patients with insulinomas. Despite a high incidence of neurological symptoms in patients with insulinomas, Daggett and Nabarro did not identify any patients with involuntary movements among the 30 patients in their series nor among 220 patients reported in the literature. ${ }^{16}$

Except for the patient described by Sudhakar, adrenergic symptoms have been conspicuously absent in previously described cases of hypoglycemia-induced dyskinesias, as is true for our 2 patients. Similarly, in a review of 125 visits to an emergency room by patients with hypoglycemia and neurological symptoms, Malouf and Brust also noted adrenergic symptoms to be rare. ${ }^{9}$ It is well recognized that hypoglycemia may fail to induce an epinephrine response in patients on betablocker medication or in diabetic patients because of underlying autonomic neuropathy. It also appears that non-diabetic 
subjects, with presumably normal autonomic function, may fail to manifest classical warning signs of hypoglycemia during the development of neuroglycopenia.

It is apparent that blood glucose levels should be determined in any patient with paroxysmal dyskinesias, especially diabetics since they may develop glucopenia or hyperglycemia, both of which can cause involuntary movements. However, neurological symptoms do not necessarily correlate well with single blood glucose determinations during an attack. For instance, although patients in coma usually have lower glucose levels than those who are obtunded, considerable overlap may occur, with levels ranging from $0.1-3.3 \mathrm{mmol} / \mathrm{l} .{ }^{9}$ Our first patient's blood glucose level was $2.1 \mathrm{mmol} / \mathrm{l}$ during the documented episode of dyskinesia; however random glucose samples during asymptomatic periods ranged from 1.8 to $3.5 \mathrm{mmol} / \mathrm{l}$. Our second patient's glucose level declined from 6.0 to $2.0 \mathrm{mmol} / \mathrm{l}$ during the recorded episode of dyskinesia, but one of hemiparetic spells was associated with a glucose level in the normal range $(4.1 \mathrm{mmol} / \mathrm{l})$. However, the tendency to develop symptoms in the early morning and the prompt response to oral or intravenous glucose supports a glucopenic origin of the symptoms in our patients. Similarly, Haan's patient with diabetes developed choreoathetosis whenever the blood glucose levels dropped from mildly elevated levels into the low-normal range. ${ }^{3}$ The precipitation of symptoms in diabetic patients following blood glucose reductions into the normal range is compatible with the study by Boyle et al. who demonstrated that the mean threshold for developing hypoglycemic symptoms in normal subjects was 2.9 $\mathrm{mmol} / \mathrm{l}$ while the threshold for patients with poorly controlled diabetes was $4.3 \mathrm{mmol} / \mathrm{l} .{ }^{17}$ Whether variation in threshold is due to different rates of decline in blood glucose levels, different rates of glucose transport into the nervous system, or some other mechanism, remains to be determined. ${ }^{17}$

It is not known why some patients develop focal neurological symptoms in response to perturbations of blood glucose concentrations while most individuals do not; however, the presence of pre-existing asymptomatic brain lesions has been suggested. ${ }^{3.12}$ Indeed, at autopsy Sudhakar's patient was found to have changes in the basal ganglia "compatible with subinfarctive vascular insults";' Vincent's patient with hyperglycemia-induced choreoathetosis had a vascular malformation in the lenticular nucleus; ${ }^{14}$ and Portnoy reported a patient with hypoglycemiarelated hemiparetic attacks whose symptoms resolved following treatment of a carotid stenosis. ${ }^{18}$ However, cerebral lesions were not detected by imaging techniques in our patients nor in most patients described in the literature. ${ }^{2.3 .15 .19}$ The selective vulnerability of different brain regions to changes in glucose concentration $^{20}$ may vary among individuals, either naturally or because of disease, and thereby account for the protean neurological manifestations of hypoglycemia and hyperglycemia.

\section{ACKNOWLEDGEMENT}

We wish to thank Dr A.E. Mehta for his assistance in the endocrinological investigation of these patients.

\section{REFERENCES}

1. Golden LA. Neurological manifestations in "hypoglycemic shock" (Sakel). Ann Intern Med 1937; 11: 819-822.

2. Newman RP, Kinkel WR. Paroxysmal choreoathetosis due to hypoglycemia. Arch Neurol 1984: 41: 341-342.

3. Haan J, Kremer HPH, Padberg G. Paroxysmal choreoathetosis as presenting symptom of diabetes mellitus. J Neurol Neurosurg Psychiatry 1989; 52: 133 .

4. Parajua JL, Gallo J, Goni M, Locutura J. Coreoatetosis paroxistica en el curso de coma hipoglucemico. Med Clin (Barcelona) 1986; 87: 521 .

5. Sudhakar S, Uitti RJ, Ashenhurst EM, Munoz-Garcia D, Desai HB. Paroxysmal dystonia from hypoglycemia. Can J Neurol Sci. 1987; 14:215.

6. Padberg GW, Bruyn GW. Chorea - differential diagnosis. In: Vinken PJ, Bruyn GW, Klawans HL, eds. Handbook of Clinical Neurology. Amsterdam: Elsevier 1986: 5(49): 549-564.

7. Buruma OJS, Roos RAC. Paroxysmal choreoathetosis. In: Vinken PJ, Bruyn GW, Klawans HL, eds. Handbook of Clinical Neurology. Amsterdam: Elsevier, 1986: 5(49): 349-358.

8. Adams RD, Victor M. Principles of Neurology 4th ed. McGrawHill 1989; 852-853.

9. Malouf R, Brust JCM. Hypoglycemia: causes, neurological manifestations, and outcome. Ann Neurol 1985: 17:421-430.

10. Morres CA, Dire DJ. Movement disorders as a manifestation of nonketotic hyperglycemia. J Emerg Med 1989; 7: 359-364.

11. Bedwell SF. Some observations on hemiballismus. Neurology 1960; 10: 619-622.

12. Rector WG, Herlong HF, Moses H. Nonketotic hyperglycemia appearing as choreoathetosis or ballismus. Arch Intern Med 1982; 142: 154-155.

13. Tortoritis M, Cornish D, Thompson F. Nonketotic hyperglycemia. Arch Intern Med 1982; 142: 1405.

14. Vincent FM. Hyperglycemia-induced hemichoreoathetosis: the presenting manifestation of a vascular malformation of the lenticular nucleus. Neurosurgery 1986; 18: 787-790.

15. Foster JW, Hart RG. Hypoglycemic hemiplegia: two cases and a clinical review. Stroke 1987; 18: 944-946.

16. Daggett P, Nabarro J. Neurological aspects of insulinomas. Postgrad Med J 1984; 60: 577-581.

17. Boyle PJ, Schwartz NS, Shah SD, Clutter WE, Cryer P. Plasma glucose concentrations at the onset of hypoglycemic symptoms in patients with poorly-controlled diabetes and in nondiabetics. $\mathrm{N}$ Engl J Med 1988; 318: 1487-1492.

18. Portnoy HD. Transient "ischemic" attacks produced by carotid stenosis and hypoglycemia. Neurology 1965; 15: 830-832.

19. Wallis WE, Donaldson I, Scott RS, Wilson J. Hypoglycemia masquerading as cerebrovascular disease (hypoglycemic hemiplegia). Ann Neurol 1985; 18: 510-512.

20. Auer RN, Siesjo BK. Biological differences between ischemia, hypoglycemia, and epilepsy. Ann Neurol 1988; 24: 699-707. 